\title{
Enfrentamento da violência no ambiente escolar na perspectiva dos diferentes atores
}

Verônica Borges Kappel(a) Daniela Tavares Gontijo(b)

Marcelo Medeiros ${ }^{(\mathrm{c})}$

Estela Maria Leite Meirelles Monteiro(d)

Kappel VB, Gontijo DT, Medeiros M, Monteiro EMLM. Coping with violence in the school environment from the perspectives of different players. Interface (Botucatu). 2014;

18(51):723-35.

Violence involving adolescents today is a public health problem present in various social spaces, including schools. This study had the aim of describing and analyzing the process of coping with violence in schools from the perspectives of different players within the school community. There were 27 participants in the study, including managers, teachers, students, general service assistants and parents of students at a public school. Data were gathered through semi-structured interviews and, after transcription, these data were analyzed through content analysis. It was found that the procedures adopted by the different players in the school, in cases of violence, expressed the difficulties. The strategies related to the experiences and roles played by each of them. The potential to construct and strengthen dialogue between the different players of the school community and within an intersectoral coping network was shown.

Keywords: Violence. School healthcare. Adolescent. Intersectoral action.
Atualmente, a violência envolvendo adolescentes configura-se como um problema de saúde pública presente em diferentes espaços sociais, inclusive na escola. Este estudo tem como objetivo descrever e analisar o processo de enfrentamento da violência escolar na perspectiva dos diferentes atores de uma comunidade escolar. Participaram do estudo 27 atores, entre: gestores, professores, alunos, auxiliares de serviços gerais e pais de alunos de uma escola pública. Os dados foram coletados por meio de entrevistas semiestruturadas e analisados por intermédio de análise de conteúdo depois de transcritas. Identifica-se que os procedimentos adotados na escola, em casos de violência, pelos diferentes atores, expressam as dificuldades e as estratégias relacionadas às experiências e aos papéis desempenhados por cada um. Aponta-se a potencialidade da construção e fortalecimento do diálogo entre os diferentes atores da comunidade escolar e de uma rede de enfrentamento intersetorial.

Palavras-chave: Violência. Saúde escolar. Adolescente. Ação intersetorial.

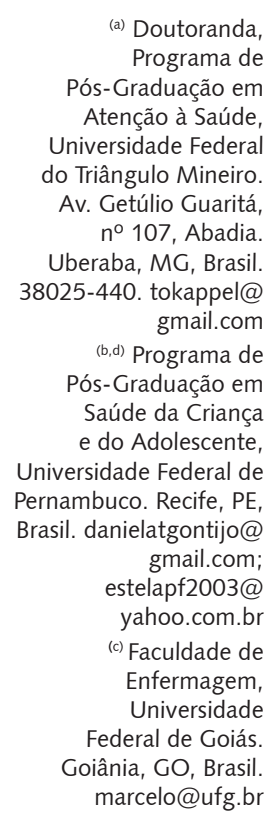

(a) Doutoranda, Programa de Pós-Graduação em Atenção à Saúde, Universidade Federal do Triângulo Mineiro. Av. Getúlio Guaritá, no 107, Abadia. Uberaba, MG, Brasil. 38025-440. tokappel@ gmail.com (b,d) Programa de Pós-Graduação em Saúde da Criança e do Adolescente, Universidade Federal de Pernambuco. Recife, PE, Brasil.danielatgontijo@ gmail.com; estelapf2003@ yahoo.com.br (c) Faculdade de Enfermagem, Universidade Federal de Goiás. Goiânia, GO, Brasil. marcelo@ufg.br 


\section{Introdução}

A violência envolvendo adolescentes configura-se como um problema de saúde pública presente em diferentes espaços sociais, inclusive na escola ${ }^{1-3}$. A violência escolar, assim como a violência em geral, incorpora tanto a perspectiva mais explícita, como a agressão entre indivíduos, quanto a violência simbólica que ocorre por meio das regras, normas e hábitos culturais de uma sociedade desigual ${ }^{4}$.

A Organização Mundial de Saúde (OMS) compreende a violência em uma perspectiva ecológica resultante da interação de dimensões (níveis) individuais, relacionais, comunitárias e sociais. $O$ primeiro nível concentra-se na identificação e análise das características da pessoa que aumentam a possibilidade de ser uma vítima ou uma perpetradora da violência. O segundo nível discute a maneira pela qual as relações sociais mais próximas interferem no risco para vitimização e perpetração pela/ da violência. O terceiro nível analisa os contextos comunitários em que as relações se inserem (por exemplo, escolas), que contribuem ou não para as situações de violência. O último nível analisa os fatores sociais mais amplos que influenciam os índices de violência, como as normas culturais, as políticas de saúde e educacionais 5 .

A violência escolar tem sido, especificamente, alvo de estudos construídos, geralmente, a partir da perspectiva dos diferentes atores do cenário escolar de forma isolada ${ }^{6-8}$.

Na Pesquisa Nacional sobre Saúde do Escolar, realizada com 60.973 estudantes nas capitais brasileiras, foi constatado que 5,5\% já haviam faltado às aulas devido à sensação de insegurança e $12,9 \%$ relataram envolvimento em brigas com agressão física nos trinta dias que antecederam a pesquisa?.

Diante deste quadro de violência no âmbito escolar, se faz necessário refletir acerca de possibilidades de proteção aos adolescentes e enfrentamento ao fenômeno. O desenvolvimento de fortes vínculos entre pais e filhos, uma disciplina fundamentada no exercício do diálogo, adoção de políticas para a escola como um todo, currículos que incentivam o desenvolvimento de atitudes e comportamentos não violentos e não discriminatórios são alguns dos fatores que tendem a proteger os adolescentes da violência escolar'.

O enfrentamento da violência escolar, além de considerar dados sobre sua magnitude, também perpassa pela compreensão do contexto social que a produziu, considerando os fatos e a representação que ela adquire para as pessoas, familiares e comunidades que interagem neste contexto ${ }^{10,11}$.

Neste sentido, objetivou-se, nesta pesquisa, descrever e analisar como ocorre o processo de enfrentamento da violência escolar na perspectiva dos diferentes atores que compõem o cotidiano de uma comunidade escolar.

\section{Percurso metodológico}

Estudo descritivo de abordagem qualitativa, realizado em uma escola pública de cidade de médio porte da região do Triângulo Mineiro. A escola foi escolhida a partir de pesquisas anteriores que apontaram a existência da violência, tanto na instituição como na comunidade em que esta se insere ${ }^{12,13}$.

Foram convidados a participar do estudo integrantes da comunidade escolar, que frequentavam a escola no período matutino, assim divididos:

Grupo 1: Gestores da escola (cargos de direção, vice-direção e pedagogia).

Grupo 2: Professores do $9^{\circ}$ ano do Ensino Fundamental, com exercício profissional mínimo de seis meses - tempo mínimo considerado para que estes tenham a oportunidade de conhecer a dinâmica da escola.

Grupo 3: Auxiliares de serviços gerais (serviços de limpeza, cozinha e portaria) que trabalhavam há, no mínimo, seis meses. 
Grupo 4: Estudantes do $9^{\circ}$ ano do Ensino Fundamental, com até 18 anos, e cujos responsáveis autorizaram a participação na pesquisa.

Grupo 5: Responsáveis legais/pais dos estudantes do $9^{\circ}$ ano do Ensino Fundamental.

Para assegurar a confidencialidade e o anonimato, foi atribuído um código a cada entrevistado com idade superior a 18 anos e um pseudônimo escolhido pelos adolescentes. A definição do número de participantes foi realizada por procedimentos de saturação por exaustão ${ }^{14}$.

Os dados foram coletados no período de março a junho de 2012, por meio de entrevistas individuais realizadas com gestores, professores, auxiliares de serviços e pais, sendo que os alunos participaram de uma entrevista coletiva. O roteiro de entrevistas, comum a todos os grupos, abordou questões relativas: ao que os participantes entendiam por violência escolar, aos procedimentos adotados nestas situações, à identificação dos responsáveis pelos atos violentos, às formas de enfrentamento da violência escolar, e às dificuldades inerentes a este processo.

As entrevistas foram gravadas, transcritas e submetidas à análise de conteúdo temática numa perspectiva qualitativa. Inicialmente, realizou-se uma leitura compreensiva e exaustiva do conjunto dos dados, seguida de procedimentos de exploração do material e identificação das ideias centrais dos fragmentos de fala. Estas ideias centrais foram distribuídas em núcleos de sentido, que, agrupados, resultaram nas categorias temáticas: "concepções sobre a violência escolar"; "procedimentos adotados pela escola"; "responsáveis pelo enfrentamento"; "dificuldades no processo de enfrentamento" e "possíveis estratégias de enfrentamento". Finalmente, foi construída uma síntese interpretativa que articulou os dados encontrados na pesquisa, os objetivos do estudo e o referencial teórico adotado ${ }^{15}$. Ressalta-se que o processo de categorização dos dados referentes às estratégias de enfrentamento foi diretamente subsidiado pelo modelo teórico de compreensão da violência proposto pela $\mathrm{OMS}^{5}$.

O projeto de pesquisa foi aprovado pelo Comitê de Ética em Pesquisa da UFTM, protocolo 2094, sendo as entrevistas realizadas em locais que asseguraram a privacidade dos grupos de participantes e conduzidas após a assinatura dos Termos de Consentimento Livre e Esclarecido.

\section{Resultados e discussão}

\section{Caracterização dos participantes do estudo}

Participaram do estudo 27 pessoas dos diferentes grupos. O grupo dos gestores foi composto em sua totalidade, correspondendo a três mulheres com média de cinquenta anos de idade e tempo superior a 25 anos de exercício profissional para duas entrevistadas (Tabela 1).

Todos os nove professores da escola participaram, os quais foram, majoritariamente, do sexo feminino, com idade média de 43 anos; e, destes, sete tinham mais de dez anos de trabalho na área da educação (Tabela 2). As três auxiliares de serviços gerais eram mulheres, com média de 46 anos e tempo de trabalho superior a nove anos (Tabela 3).

Constituíram o grupo dos estudantes (Tabela 4) sete alunos do $9^{\circ}$ ano, sendo quatro meninas e três meninos, que, em sua maioria, tinham mais de cinco anos de frequência nesta escola e média de idade de 14 anos.O grupo dos responsáveis legais foi composto por cinco membros, com predomínio de mães, com idade média de 36 anos (Tabela 5).

Tabela 1. Perfil dos gestores

\begin{tabular}{lccccc}
\hline Identificação & Sexo & Idade & $\begin{array}{c}\text { Tempo de trabalho } \\
\text { na educação (anos) }\end{array}$ & $\begin{array}{c}\text { Tempo de trabalho } \\
\text { na escola (anos) }\end{array}$ & $\begin{array}{c}\text { Tempo de trabalho } \\
\text { na gestão (anos) }\end{array}$ \\
\hline GESTOR 1 & $\mathrm{F}$ & 45 & 27 & 27 & 7 \\
GESTOR 2 & $\mathrm{F}$ & 47 & 30 & 27 & 15 \\
GESTOR 3 & $\mathrm{F}$ & 58 & 40 & 2 & 1 \\
\hline
\end{tabular}

Fonte: dados empíricos 
Tabela 2. Perfil dos professores do nono ano do ensino fundamental

\begin{tabular}{lcccc}
\hline Identificação & Sexo & Idade & Tempo de trabalho na educação (anos) & Tempo de trabalho na escola (anos) \\
\hline PROF 1 & $\mathrm{F}$ & 37 & 18 & 4 \\
PROF 2 & $\mathrm{M}$ & 51 & 18 & 17 \\
PROF 3 & $\mathrm{F}$ & 31 & 8 & 2 \\
PROF 4 & $\mathrm{M}$ & 55 & 30 & 26 \\
PROF 5 & $\mathrm{F}$ & 36 & 18 & 6 \\
PROF 6 & $\mathrm{F}$ & 42 & 21 & 2 \\
PROF 7 & $\mathrm{F}$ & 34 & 7 & $1 \mathrm{6}$ \\
PROF 8 & $\mathrm{F}$ & 50 & 28 & 23 \\
PROF 9 & $\mathrm{F}$ & 47 & 12 & 3 \\
\hline
\end{tabular}

Fonte: dados empíricos

Tabela 3. Perfil dos auxiliares de serviços gerais

\begin{tabular}{lcccc}
\hline Identificação & Sexo & Idade & Tempo de trabalho na educação (anos) & Tempo de trabalho na escola (anos) \\
\hline Aux 1 & $\mathrm{F}$ & 37 & 17 & 17 \\
Aux 2 & $\mathrm{F}$ & 54 & 9 & 9 \\
Aux 3 & $\mathrm{F}$ & 48 & 20 & 13 \\
\hline
\end{tabular}

Fonte: dados empíricos

Tabela 4. Perfil dos estudantes do nono ano do ensino fundamental

\begin{tabular}{lccc}
\hline Pseudônimos & Sexo & Idade (anos) & Tempo que estuda na escola \\
\hline Roberta & $\mathrm{F}$ & 14 & 5 anos \\
Gabriela & $\mathrm{F}$ & 14 & 9 anos \\
Vitória & $\mathrm{F}$ & 13 & 6 meses \\
Alice & $\mathrm{F}$ & 14 & 9 anos \\
João & $\mathrm{M}$ & 13 & 3 anos \\
Teddy & $\mathrm{M}$ & 14 & 2 anos e 6 meses \\
Will Smith & $\mathrm{M}$ & 13 & 10 anos \\
\hline
\end{tabular}

Fonte: dados empíricos

Tabela 5. Perfil dos responsáveis legais pelos alunos do nono ano do ensino fundamental

\begin{tabular}{lcc}
\hline Identificação & Sexo & Idade (anos) \\
\hline MÃE 1 & $\mathrm{F}$ & 35 \\
MÃE 2 & $\mathrm{F}$ & 43 \\
MÃE 3 & $\mathrm{F}$ & 32 \\
MÃE 4 & $\mathrm{F}$ & 34 \\
PAI 1 & M & 38 \\
\hline
\end{tabular}

Fonte: dados empíricos

Foi observada menor adesão dos alunos e de seus pais, embora tenham sido desenvolvidas diferentes estratégias de mobilização e incentivo à participação. Este fato suscita a reflexão acerca da intensidade e complexidade do fenômeno da violência escolar manifesto no cenário da pesquisa, pois se acredita que os estudantes tenham tido receio de participar devido à grande manifestação da violência na sala e a possível cultura do medo impregnada. A limitada participação dos pais dos 
alunos na pesquisa também sinaliza para uma possível limitação no envolvimento destes para com as atividades desenvolvidas pela escola (conforme discutido posteriormente).

\section{Concepções sobre a violência escolar}

Embora não tenha sido objetivo deste trabalho discutir os significados da violência escolar, a partir do conteúdo trazido pelos participantes, foi possível identificar aspectos relacionados à compreensão destes sobre o que é ou não uma situação violenta na escola. Essa compreensão, embora não explorada em profundidade, traz importantes subsídios para as reflexões apontadas nas categorias subsequentes.

Neste sentido, para conceituar a violência escolar, os diferentes grupos fizeram referência: aos locais de ocorrência dos atos violentos, à tipologia e aos envolvidos nestes eventos. O espaço da saída das aulas, seguido da sala de aula, pátio e banheiros, foram os mais citados pelos participantes como lócus da violência, caracterizada, sobretudo, como física e psicológica, entre os alunos.

“Eu acho que agressões verbais [...] é [...] tanto violência verbal, física também [...]. Aí na física entra chute, soco, alguma coisa assim, xingamentos, apelidos [...]". (aluno João)

Todos os grupos, com exceção dos alunos, ressaltaram atos agressivos (violência psicológica, física e contra o patrimônio) destes em relação aos professores, sendo que os adolescentes também relataram situações de vitimização psicológica causadas pelos professores: "[...] Como você fala com o outro, se refere a ele... aquele que usa da sua autoridade para inibir o outro..." (prof. 3); "[...] e o aluno vai e agride ele com palavras" (aux. 1).

Esses aspectos apontados para definir a violência escolar refletem as dificuldades de conceituação do fenômeno já apontada na literatura ${ }^{6,13,16}$. Neste estudo, e em outras pesquisas sobre o tema, observou-se uma maior visibilidade das violências física e psicológica, e do envolvimento de alunos e professores nas situações de violência ${ }^{5,7,17}$.

Os dados mostram que a compreensão da violência escolar se constrói a partir de situações de violência envolvendo somente os alunos ou estes e os professores. Embora sejam os atores mais citados quando se discute a violência escolar, qualquer pessoa que esteja envolvida na comunidade escolar pode se configurar como um autor, vítima e/ou testemunha de atos violentos e, por conseguinte, também se constituir corresponsável pela sua prevenção $0^{4,18}$.

\section{Procedimentos adotados pela escola nas situações de violência escolar}

Os participantes foram solicitados a relatar quais os procedimentos adotados pela escola, em casos de violência escolar, sendo a escuta dos alunos envolvidos e de seus pais apontada por todos os grupos de atores:

Pai 1: " [...] sempre quando acontece isso é chamado o pai [...] os pais das crianças, tanto do agressor quanto da vítima [...] para tá passando o acontecido pra ver o que que a gente pode tá melhorando com aquela criança [...] que é agressora ... a criança também [...] que é agredida [...]".

Além da escuta, não foi possível caracterizar outros procedimentos uniformes, e cada grupo apontou caminhos diferentes adotados pela escola nas situações de violência escolar. Somente os gestores trouxeram a questão do regimento escolar como guia no enfrentamento ao fenômeno:

Gestor 2: “[...] Então a primeira coisa é ouvir, depois é o encaminhamento [...] o professor é o primeiro que ouviu [...] depois conversa com a pedagoga [...] depois ele vem pra gente [...] a gente conversa [...] depois olha o regimento e vê o que que foi descumprido no regimento da escola com aquela situação". 
Por outro lado, os familiares foram os únicos a trazerem o encaminhamento para órgãos de defesa da criança e do adolescente:

Mãe 4: “Eu acho que encaminha pra mãe [...] se a mãe não resolver vai pro tutelar de menor, tutelar não, como é que chama? Primeiro vê se a mãe resolve, se a mãe não resolver vai pro conselho".

Destaca-se que uma das mães, dois professores e cinco alunos explicitaram desconhecimento sobre os procedimentos adotados pela escola em casos de violência.

Percebeu-se que os procedimentos adotados pela escola, nos casos de violência escolar, encontramse dispersos e não partilhados pelos diferentes grupos de atores escolares. O não-reconhecimento dos procedimentos adotados na instituição pode contribuir para a perpetuação de práticas agressivas, para o não-entendimento acerca das consequências dos atos realizados e para o fortalecimento da crise de autoridade existente nos dias atuais.

Lobato e Placco ${ }^{8}$ destacam que, diante das situações de violência, a escola tende a adotar medidas repressivas, o que não soluciona o problema substancialmente e a longo prazo.

Para o enfrentamento da violência escolar, aponta-se a necessidade de se pensar na importância da vivência de discussões horizontais e democráticas entre os diversos atores que compõem este cenário, objetivando a construção coletiva dos procedimentos e sua divulgação na comunidade escolar como um todo. Considera-se que uma efetiva participação democrática nas decisões educacionais possibilita que os indivíduos se corresponsabilizem pelos acertos e desacertos do processo educativo, o que contribui para uma maior possibilidade de resolução de situações relacionadas à violência escolar ${ }^{1}$.

\section{Responsáveis pelo enfrentamento da violência escolar}

Quando questionados sobre quem deve ser responsabilizado pelo enfrentamento da violência escolar, a família e os atores que convivem no contexto escolar foram relatados por todos os grupos, em diferentes níveis de prioridade.

A percepção da família como a principal responsável por este enfrentamento foi destacada nos grupos dos professores, auxiliares de serviços e familiares: "Os pais, a família [...] são o forte. A família com exemplos" (prof. 5).

Os gestores apontaram que todas as pessoas que convivem no espaço escolar são responsáveis pelo estabelecimento de medidas de enfrentamento à violência, destacando o papel dos adultos neste processo:

\footnotetext{
“Todos nós somos responsáveis [...] do diretor ao faxineiro [...] Nós somos os agentes... nós que temos que mudar as coisas [...] estamos formando-os [...] não é eles que nos formam [...] então a mudança tem que vir da gente". (gestor 2)
}

Para os alunos, eles próprios, no estabelecimento das relações no contexto escolar, são os únicos responsáveis pelo enfrentamento, como salientou o aluno Will: "A gente mesmo [...]". Esta compreensão aponta para uma possível autoculpabilização pelas situações de violência e para uma restrita percepção de outros atores envolvidos com o fenômeno.

Apenas no grupo de professores, a sociedade, de uma forma geral, foi citada como responsável pelo processo de enfrentamento da violência: "[...] a sociedade [...] todos porque depois quem que vai sofrer com a violência [...]? A sociedade, lógico. Nós somos todos cidadãos" (prof. 6).

Embora todos os atores que convivem e se relacionam ao espaço escolar devam ser considerados como responsáveis na prevenção e combate das situações violentas, o papel dos professores, neste processo, deve ser destacado. Acreditar e investir na capacidade dos alunos, criar situações educativas de forma que eles possam se expressar, propiciando vivência satisfatória e entrosamento, constitui uma forma de colaborar com a diminuição da violência dentro do ambiente escolar ${ }^{19}$. 
Para isso, existem alguns elementos que deveriam ser constitutivos da formação profissional dos educadores: a necessidade de perceber que a violência não é algo "natural", e sim uma questão que precisa ser pensada a partir do contexto; a adequação da adoção de atitudes ativas e não reativas aos problemas que ocorrem no contexto escolar, de forma preventiva; o respeito ao contexto em que a escola está inserida, considerando que o problema da violência é complexo e heterogêneo; a necessidade de constante qualificação profissional a respeito da violência escolar; a importância de se buscar a participação dos pais nos projetos realizados pela escola, assim como o estabelecimento de parcerias com a comunidade onde escola está inserida e com os serviços oferecidos por ela ${ }^{1}$.

No entanto, em relação à responsabilização do professor no enfrentamento da violência escolar, é importante refletir sobre os limites concretos impostos pelo cotidiano a estes, que, muitas vezes, vivenciam situações de vitimização e precárias condições de trabalho ${ }^{12,20}$.

Além do papel dos educadores no enfrentamento à violência escolar, a participação dos demais atores, serviços e instituições pertencentes à rede de atenção à criança e ao adolescente - parcialmente citada pelas mães, como corresponsáveis pelo enfrentamento ao fenômeno - deve ser problematizada. O trabalho em rede é um mecanismo que pode ser eficaz no enfrentamento à violência escolar porque: favorece uma visão global das situações, permite o planejamento de ações integradas, contribui para o compartilhamento de responsabilidades, possibilitando que cada setor atue com foco nas questões que lhe cabem, trabalhando, concomitantemente, nas interfaces existentes com outras esferas ${ }^{10}$.

\section{Dificuldades no processo de enfrentamento à violência escolar}

Os participantes do estudo também foram solicitados a refletir sobre quais são as dificuldades no enfrentamento à violência escolar.

Uma dificuldade relatada por todos os grupos, exceto pelos auxiliares de serviços gerais, se referiu às características consideradas típicas dos adolescentes, com destaque para: posturas de contestação, de confronto de ideias, e a valorização de brincadeiras consideradas "agressivas" no contexto escolar.

"Muitos alunos, eu acho que [...] eles não aceitam as ideias dos outros alunos [...]" (aluno João)

Mãe 2: "eu acho assim, entre os alunos mesmo sabe [...] eles tem que ter um comportamento mais legal, parar de brincadeira [...] Porque tudo começa assim, igual eu te falei... de brincadeira [...] aí depois até um apelar [...]".

A fala desta mãe explicita uma naturalização da adolescência como um período de crises, traz à tona a necessidade de uma ampliação na compreensão desta fase do desenvolvimento humano. Essa ampliação se relaciona, diretamente, à compreensão de que o ser humano se caracteriza pela sua historicidade, ou seja, os adolescentes vivenciam as suas experiências, constroem-se como cidadãos, e delineiam a realidade que os cerca em meio às (im)possibilidades concretas de suas situações de vida ${ }^{21}$. Nesse sentido, compreende-se que as manifestações tidas como naturais na adolescência, entre elas as condutas violentas, podem se caracterizar como uma reprodução acrítica da realidade vivenciada por estes nos seus diferentes contextos de vida, incluindo a família e a própria escola. Essa compreensão, contrária a uma representação fatalista da situação, consoante ao defendido por Freire ${ }^{21}$, amplia a percepção de que a mudança, apesar de difícil, é possível, uma vez que a realidade não é dada, e sim construída pelos diferentes sujeitos.

A falta de interesse e a participação limitada da família nas atividades escolares foram outros fatores apontados pelos grupos de participantes que dificultam o combate da violência:

Gestor 3: “É [...] Nossa, tem família que [...] Não vamos longe não [...] Hoje eu convoquei [...] não, convidei [...] convoquei é feio [...] convidei 58 pais para virem a reunião [...] quantos pais vieram? 10?". 
Tal como explicitado anteriormente, todos os grupos identificaram a família como uma das principais responsáveis pelo enfrentamento da violência escolar, no entanto, percebe-se que sua participação é limitada. Essa limitação pode se relacionar ao processo de desestruturação social, econômica, e de valores morais e culturais, que acomete as famílias, sobretudo aquelas em situação de exclusão social, e restringe as possibilidades de estas oferecerem o suporte social para as crianças e os adolescentes.

O núcleo familiar detém a responsabilidade da educação primária junto às crianças, em termos de modelos que ela terá e do desempenho de seus papéis na sociedade. A família tem como tarefa central propiciar o desenvolvimento e aquisição de comportamentos considerados adequados aos padrões sociais vigentes, considerando as questões culturais. Entretanto, inúmeros fatores podem comprometer o acesso satisfatório à educação primária, constituindo um fator de constrangimento para o familiar lidar com essa realidade ${ }^{22}$.

Outra dificuldade apontada por todos os atores (exceto os alunos) se refere à fragilidade das políticas educacionais no oferecimento de condições positivas de trabalho aos professores, o que provoca desmotivação destes para o exercício profissional e para o desenvolvimento de medidas de enfrentamento da violência escolar: "Falta mais força de vontade da parte da prefeitura [...] o apoio deles" (mãe 1).

Destaca-se que apenas o grupo dos gestores pontuou, como fator limitante ao enfrentamento da violência, a fragilidade da rede de proteção à criança e ao adolescente:

Gestor 1: “[...] nem sempre você consegue um psicólogo para aquela criança [...] então são entraves ou dificuldades que você não tem uma [...] rede eficaz ainda [...] você tem um PSF que você pode indicar, mas não tem as vezes o profissional pra atende a demanda".

Além disso, destacou-se a percepção dos auxiliares de serviços gerais de que as políticas de proteção à criança e o adolescente podem se caracterizar como um obstáculo ao enfrentamento da violência escolar quando limitam a possibilidade de estabelecimento de medidas punitivas para os adolescentes:

Aux. 3: "Hoje em dia a lei protege muito [...] eu acho que a principal coisa pra diminuir essa violência é essa lei que eles puseram [...] até 18 anos é criança e tudo [...] não pode ser preso [...] tem que pagar... eles fazem porque sabem que não dá em nada".

Esta percepção reforça uma "cultura da culpabilização" do adolescente frente ao processo da violência escolar, em detrimento do envolvimento de todos os atores no enfrentamento deste fenômeno. Além disso, nesta perspectiva, há a valorização de medidas punitivas em detrimento da problematização e enfrentamento das condições estruturais relacionadas à violência juvenil.

\section{Estratégias de enfrentamento da violência escolar}

No que se refere às possíveis estratégias de enfrentamento da violência escolar, inicialmente, destaca-se que este foi o conteúdo mais explorado pelos participantes do estudo durante as entrevistas, quando comparado aos anteriormente citados.

Considerando o modelo teórico da $\mathrm{OMS}^{5}$, é possível observar, nas falas dos participantes, que as estratégias identificadas focam ações comunitárias e, em menor intensidade, ações individuais, relacionais e sociais.

No nível individual, a autoavaliação em relação às posturas e comportamentos comumente adotados no cotidiano escolar foi partilhada por todos os grupos, com exceção dos auxiliares de serviços gerais.

“[...] É quando você começa a saber que você faz parte daquilo ali e que você também tem coisa pra jogar fora [...] e que você também tem coisa pra melhorar [...] porque você também 
está contribuindo pra esse ambiente pesado [...] É quando você para e olha [...] pras suas ações". (prof. 9)

A questão da reflexão acerca das próprias atitudes evidencia que os atores apresentam a preocupação em rever, constantemente, suas ações, percebendo-se parte do processo de propagação da violência escolar, o que contribui sobremaneira para a identificação de suas manifestações, assim como para elaborações de possíveis estratégias de enfrentamento e prevenção à violência escolar.

No nível relacional, salienta-se que, apenas para os pais, o maior envolvimento da família nas atividades escolares dos filhos é considerado como estratégia de enfrentamento, o que contradiz a maior responsabilização desta pela maioria dos atores, conforme anteriormente discutido.

“Eu acho que estar sempre presente na escola [...] conversar com os alunos, com a professora, com a diretora [...] eu acho que tem que fazer tipo de um acompanhamento [...] você tem que ficar no pé deles". (mãe 4)

A relação entre família e escola se estabeleceu, e ainda se mantém, a partir de situações vinculadas a algum tipo de problema, e, desta forma, pouco contribui para que as duas instituições possam construir uma parceria baseada em fatores positivos e gratificantes relacionados ao aprendizado, desenvolvimento e sucesso dos alunos. As posturas relacionadas a esta relação caracterizam-se por serem defensivas e acusativas, como se cada um buscasse se justificar e encontrar justificativas para a desarmonia que caracteriza tal relação. Assim, constitui um importante desafio, para os atores envolvidos nesta temática, a transformação da relação família-escola no sentido de que ela possa ser associada a situações positivas favorecedoras dos processos de socialização, aprendizagem e desenvolvimento 22,23 .

O diálogo entre os diferentes atores que convivem na escola foi valorizado por todos os grupos de participantes, por ser uma estratégia que permeia os níveis relacional e comunitário.

"Eu acho que o diálogo entre os alunos [...] Ah, tipo... de vez em quando colocar os alunos pra conversar... igual tipo... nós estamos aqui ... falando o que acha...". (aluna Gabriela)

Na construção deste diálogo, os alunos também destacaram a importância da vinculação afetiva:

"As pessoas que a gente gosta [...] Se a Gestor Y fala alguma coisa pra gente [...] aconselha a gente [...] a gente não vai escutar bem [...] porque a gente não gosta muito dela [...] se a Gestor X falar [...] a gente já vai escutar melhor [...] a gente já vai. [...] tentar seguir". (aluno Will)

A construção de relações verdadeiramente dialógicas se caracteriza como um processo que permite uma maior aproximação entre as pessoas que convivem na comunidade escolar e se mostra como estratégia efetiva no enfrentamento da violência ${ }^{24,25}$. Esse processo, sustentado por relações mais horizontalizadas, nas quais o respeito e o afeto medeiam a construção compartilhada e crítica do conhecimento, permite uma problematização das situações vivenciadas e uma maior responsabilização dos alunos no cotidiano da escola ${ }^{21}$.

Além disso, compreende-se que o dialogo constituiu-se como ferramenta imprescindível para a desnaturalização e desbanalização da violência no cotidiano escolar, assim como para a substituição desta como forma de resolução de conflitos $^{25}$.

De acordo com Silva ${ }^{26}$, o diálogo e o oferecimento de limite aos alunos constituem parte da democratização das relações escolares tanto internas quanto externas, e perpassam pela transformação de uma relação de coação por uma de cooperação.

A relação de coação seria uma relação de imposição, ou seja, um dos elementos da relação impõe ao outro suas formas de pensar, suas verdades e seus critérios a respeito do que é certo, errado, normal e anormal. Por outro lado, a relação baseada na cooperação diz respeito à produção de sujeitos 
autônomos, uma vez que são dependentes de acordos mútuos e baseados no diálogo. O imperativo nesse sentido é obedecer, de maneira crítica e reflexiva, aquilo que é consenso e recíproco ${ }^{26}$.

Percebeu-se que oferecer escuta ativa e dar voz aos sujeitos para que os mesmos possam expor suas percepções e, consequentemente, compreender os limites que permeiam as relações são estratégias de enfrentamento à violência escolar, que, inclusive, contribuem para o fortalecimento dessas relações de cooperação entre os atores escolares.

O esporte como estratégia no nível comunitário foi ressaltado apenas pelo grupo dos pais:

Mãe 1: "Então tem que ter alguma coisa pra incentivar os alunos a querer ir pra escola frequentar [...] ter boa nota [...] Um esporte [...] uma ocupação assim ajudaria muito [...] tipo $[\ldots]$ alguma coisa para levantar o ego dos alunos [...]".

Os atores, com exceção dos auxiliares de serviços gerais e dos gestores, pontuaram como estratégia de enfrentamento em nível comunitário o uso de metodologias diversificadas para o processo de ensino-aprendizagem:

Aluno Will: "Eu acho assim [...] Porque um trabalho no horário de uma professoras [...] ele ia ajudar porque ia ficar todos os alunos juntos, mas é [...] quando acabar esse horário ele ia continuar... então o trabalho deve ser feito nas outras aulas [...]".

Para superação de uma atitude individualizada e descontinuada, emerge que a instituição assuma sua parcela de responsabilidade pela violência que ocorre em seu interior, e, assim, valorize ações que possam diminuí-la, ou, até mesmo, erradicá-la. Dentre as ações, vale destacar: o zelo no exercício da atividade pedagógica da escola, a exigência de profissionalismo dos professores, e garantia de um ambiente propício à aprendizagem, até a democratização da gestão ${ }^{27}$.

Isso concorre para uma participação coletiva nas regras de disciplina a serem aplicadas com justiça e consistência. Para concretude dessas medidas, é necessária a sensibilização e formação de professores, e demais funcionários da comunidade escolar. Devem ser promovidas atividades como: debates para esclarecimento e sensibilização de princípios de solidariedade para toda a comunidade; como, também, a abertura da escola para a comunidade, de modo a favorecer a proximidade das famílias, a sociabilidade entre alunos e uma relação mais positiva com a instituiçãa ${ }^{27}$.

A necessidade de reorganização do sistema educacional - ação no nível social com impacto direto no nível comunitário, sobretudo no que se refere ao oferecimento de melhores condições de trabalho aos professores - foi apontada somente pelos gestores e professores:

Prof 7: "Além do salário, a condição [...] não ficar distribuindo professor pela cidade inteira [...] tentar manter em uma instituição [...] porque quando você está em uma escola só, no máximo duas, você tem como participar de todos aqueles problemas ali [...] aí você faz 2, 3, 4... nossa, o problema é da escola fulana de tal e não da outra... não, o menino é da outra [...] porque quando você está participando de uma instituição, é aquela ali, como se diz aí você veste a camisa".

As associações entre a pior percepção da qualidade de vida e saúde de professoras e as condições do ambiente e da organização do trabalho mostram a necessidade de deslocar as atuais ações preventivas, focalizadas no plano individual, para o plano das condições ambientais relacionadas ao desenvolvimento do trabalho docente ${ }^{28}$.

Conforme discutido anteriormente, as estratégias de enfrentamento da violência escolar, apontadas pelos grupos participantes, focaram-se, especialmente, em ações comunitárias e, com menor intensidade, em ações individuais, relacionais e sociais. Apesar da potencial efetividade das ações comunitárias, também é importante que se pense sobre a pertinência de ações com impacto individual, que, de acordo com Krug et al. ${ }^{5}$, objetivam aumentar o nível de fatores de proteção associados às capacidades, atitudes e crenças individuais. 
Finalmente, é importante considerar que, apesar de a dificuldade da participação da rede de proteção à criança e ao adolescente ter sido citada pelos participantes do estudo, o seu fortalecimento não foi explicitado como possível estratégia de enfrentamento da violência escolar. Neste sentido, salienta-se a importância de ações de cunho intersetorial, que englobem setores vinculados às políticas sociais básicas, defesa de direitos e responsabilização pela violação de direitos. Especificamente em relação ao setor saúde, destaca-se o potencial no estabelecimento de parcerias entre a escola e os serviços de saúde, sobretudo por meio da atenção básica em saúde na sistematização de ações de promoção da saúde e cultura da paz ${ }^{10,24}$.

\section{Considerações finais}

O enfrentamento da violência escolar se caracteriza como um processo complexo, influenciado por fatores individuais, relacionais, comunitários e sociais. A análise integrada da perspectiva de todos os atores que compõem o cotidiano escolar, proposta neste estudo, permitiu a construção de reflexões que devem ser consideradas por todos que fazem parte deste cenário.

Os sujeitos apresentaram suas concepções a partir do papel que ocupam no cenário escolar, sendo observadas, em muitos momentos, limitadas percepções na compreensão do fenômeno em estudo como um todo. Este aspecto implica a necessidade de ações que busquem a construção e compartilhamento de procedimentos, responsabilização e estratégias de enfrentamento que envolvam todos os atores. Esse compartilhamento, que deve ser construído a partir da potencialização da participação e do diálogo no cenário escolar, é vital para o estabelecimento de medidas efetivas de enfrentamento à violência.

Aponta-se a necessidade de uma ampliação do entendimento da violência escolar como um fenômeno sócio-histórico, que não se limita aos muros da escola, mas que se constrói em meio à realidade social mais ampla, e impacta não somente no processo de ensino-aprendizagem, mas em todos os âmbitos da vida, inclusive, na saúde.

Nesta perspectiva, é possível a desconstrução de visões fatalistas e que tendem à naturalização do fenômeno no cotidiano escolar, que culminam, muitas vezes, na culpabilização de determinados grupos de sujeitos e desresponsabilização de outros atores sociais implicados nesta realidade. Essas reflexões críticas e problematizadoras podem contribuir para a adoção e valorização de medidas de criação/fortalecimento de uma rede de enfrentamento da violência escolar, composta por diferentes setores sociais - aspecto superficialmente abordado por alguns dos atores escolares.

Em relação à articulação desta rede de proteção, embora esta não deva se limitar à parceria entre a Educação e a Saúde, esta apresenta potencialidade, uma vez que a violência se caracteriza como um fator com forte impacto na percepção de saúde e qualidade de vida. Neste âmbito, destacamse políticas e programas públicos (como, por exemplo, a Política Nacional de Promoção da Saúde e o Programa Saúde na Escola) de construção de ações intersetoriais direcionadas para a prevenção da violência e promoção da cultura da paz, com participação efetiva dos profissionais, sobretudo da atenção básica, no contexto escolar. Estas ações, pautadas por metodologias participativas, críticas e culturalmente pertinentes, contribuem para a construção de procedimentos e estratégias partilhadas pelos diferentes atores do cenário escolar.

Considera-se que as possibilidades do enfrentamento à violência escolar, especialmente no contexto do ensino público, cenário deste estudo, estão diretamente relacionadas às políticas educacionais e ao impacto destas nas condições de trabalho de professores e gestores, uma vez que a precariedade vivenciada limita a participação destes atores-chave neste processo.

Finalmente, a violência escolar configura-se como um fenômeno cujo enfrentamento perpassa, também, por mudanças mais amplas, não só nas políticas educacionais, mas, também, nas políticas sociais, no sentido de fortalecimento da família enquanto fonte de suporte social para as crianças e os adolescentes. 


\section{Colaboradores}

Verônica Borges Kappel, Daniela Tavares Gontijo e Marcelo Medeiros trabalharam na concepção e execução do projeto de pesquisa, assim como na elaboração e revisão do manuscrito. Estela Maria Meirelles realizou a revisão final do manuscrito.

\section{Referências}

1. Gomes CS, Lira A, Caldas DB, Lima DA, Lopes RB. Violências nas escolas: decifrai-me ou vos devoro. Sociol Prob Prat. 2013; 1(71):39-59.

2. Netto L, Rodrigues RN, Costa MA, Santos J, Tatagiba GA. Experiências e especificidades da violência escolar na percepção de funcionários de uma escola pública. Rev Enferm UFSM. 2012; 2(3):591-600.

3. Alves RA, Pinto LMN, Silveira AM, Oliveira GL, Melo EM. Homens, vítimas e autores de violência: a corrosão do espaço público e a perda da condição humana. Interface (Botucatu). 2012; 16(43):871-83.

4. Stelko-Pereira AC, Williams LCA. Reflexões sobre o conceito de violência escolar e a busca por uma definição abrangente. Temas Psicol. 2010; 18(1):45-55.

5. Krug EG, Dahlberg LL, Mercy AJ, Zwi AB, Lozano R, organizadores. Relatório mundial sobre violência e saúde. Genebra: Organização Mundial da Saúde; 2002.

6. Costa MC, Silva EB, Jahn AC, Dalmolin IS, Santos M, Silva CM. Representações sociais da violência escolar na expressão de jovens estudantes. Rev Eletron Enferm. 2012; 14(3):514-22.

7. Malta DC, Souza ER, Silva MMA, Silva CS, Andreazzi MAR, Crespo C, et al. Vivência de violência entre escolares brasileiros: resultados da Pesquisa Nacional de Saúde do Escolar (PENSE). Cienc Saude Colet. 2010; 15(2):3053-63.

8. Lobato VS, Placco VMNS. Concepções de professores sobre questões relacionadas à violência na escola. Psicol Educ [Internet]. 2007 [cited 2014 fev 10]; 1(24):73-90. Available from: http://pepsic.bvsalud.org/pdf/psie/n24/v24a06.pdf

9. Unicef. Relatório de pesquisa: violência contra crianças [Internet]. Brasília (DF): Assembléia Geral das Nações Unidas; 2006. [cited 2013 Jun 4]. Available from: http:// www.unicef.org/brazil/pt/Estudo_PSP_Portugues.pdf

10. Kappel VB. O significado da violência escolar na perspectiva de diferentes atores de uma comunidade escolar do município de Uberaba - MG [dissertação]. Uberaba: Universidade Federal do Triângulo Mineiro; 2012.

11. Schenker $M$, Cavalcanti FG. Famílias que se comunicam através de violências. In: Njaine K, Assis SG, Constantino P, organizadores. Impactos da violência na saúde. 2a ed. Rio de Janeiro: Fiocruz; 2010. p. 197-213.

12. Maricone MR, Alves HC, Gontijo DT. Levantamento e análise de registros e eventos de defesa social (REDS) envolvendo crianças e adolescentes no município de Uberaba em 2010: subsídios para ações intersetoriais. Rev LEVS/ Unesp-Marília. 2012; 1(9):113-28.

13. Gontijo DT, Julião $\mathrm{CH}$, Kappel VB, Alves HC, Farinelli MR. Identificação e caracterização da violência escolar: subsídios para ações de enfrentamento. Mundo Saude. 2013; 37(1):16-24.

14. Fontanella BJB, Ricas J, Turato, ER. Amostragem por saturação em pesquisas qualitativas em saúde: contribuições teóricas. Cad Saude Publica. 2008; 24(1):17-27.

15. Gomes R. Análise e interpretação de dados de pesquisa qualitativa. In: Minayo MCS, Gomes SFD, organizadores. Pesquisa social: teoria, método e criatividade. Rio de Janeiro: Vozes; 2008. p. 79-108. 
16. Araujo LS, Coutinho MPL, Miranda RS, Saraiva ERA. Universo consensual de adolescentes acerca da violência escolar. Psico-US. 2012; 17(2):243-51.

17. Rocha KMM, Farias GM, Gurgel AKC, Costa IKF, Freitas MCS, Souza AAM. Violência na escola vivida por professores, funcionários e diretores. Rev Rene. 2012; 13(5):1034-44.

18. Silva JMAP, Salles LMF. A violência na escola: abordagens teóricas e propostas de prevenção. Educar Rev. 2010; 1(esp):217-32.

19. Assis SG, Avanci JQ, Oliveira RVC. Violência escolar e auto-estima de adolescentes. Cad Pesqui. 2006; 36(127):35-50.

20. Souza KOJ. Violência em escolas públicas e a promoção da saúde: relatos e diálogos com alunos e professores. Rev Bras Promoc Saude. 2012; 25(1):71-9.

21. Freire P. Pedagogia da autonomia: saberes necessários à prática educativa. São Paulo: Paz e Terra; 2011.

22. Oliveira $\mathrm{CBE}$, Marinho- Araujo CM. A relação família-escola: intersecções e desafios. Estud Psicol. 2010; 27(1):99-108.

23. Marcondes KHB, Sigolo SRRL. Comunicação e envolvimento: possibilidades de interconexões entre família-escola? Paidéia. 2012; 22(51):91-9.

24. Ministério da Saúde. Metodologias para o cuidado de crianças, adolescentes e famílias em situação de violências. Brasília (DF): Ministério da Saúde; 2011.

25. Assis SG, Constantino P, Avanci JQ. Impactos da violência na escola: um diálogo com professores. Rio de Janeiro: Fiocruz; 2010.

26. Silva NP. Ética, indisciplina e violência nas escolas. 6a ed. Petrópolis: Vozes; 2012.

27. Leme MIS. A gestão da violência escolar. Dialogo Educ [online] 2009; 9(28):541-55.

28. Jardim R, Barreto SM, Assunção AA. Trabalho, qualidade de vida e disfonia em professoras. Cad Saude Publica. 2007; 23(10):2439-61.

Kappel VB, Gontijo DT, Medeiros M, Monteiro EMLM. Enfrentamiento de la violencia en el ambiente escolar bajo la perspectiva de los diferentes actores. Interface (Botucatu). 2014; 18(51):723-35.

Actualmente, la violencia que envuelve a adolescentes se configura como un problema de salud pública presente en diferentes espacios sociales, incluso en la escuela. El objetivo de este estudio es describir y analizar el proceso de enfrentamiento de la violencia escolar en la perspectiva de los diferentes actores de una comunidad escolar. En el estudio participaron 27 actores entre gestores, profesores, alumnos, auxiliares de servicios generales y padres de alumnos de una escuela pública. Los datos se colectaron por medio de entrevistas semi-estructuradas y se analizaron por medio de análisis de contenido después de realizada la transcripción. Se identificó que los procedimientos adoptados en la escuela en casos de violencia, por parte de los diferentes actores, expresan las dificultades y las estrategias se relacionan con las experiencias y los papeles desempeñados por cada uno. Se señala el potencial de la construcción y del fortalecimiento del diálogo entre los diferentes actores de la comunidad escolar y de una red de enfrentamiento intersectorial.

Palabras clave: Violencia. Salud escolar. Adolescente. Acción intersectorial. 
